\title{
Carta pública de tutela y curadela judía (siglo XV)
}

Encarnación MARÍN PADILLA

CSIC, Madrid

El estudioso que trabaja con documentación de los Archivos de Protocolos de notarios cristianos aragoneses del siglo XV, encuentra con cierta frecuencia alusiones a cartas de tutela y curadela en las que quienes desempeñaban funciones jurídicas, fueran cristianos, judíos o moros, asignaban tutores y curadores, llamados dativos, de las personas y los bienes de menores para el cuidado de los pupilos y la administración de sus propiedades. Estas asignaciones tenían lugar cuando el padre, la madre o ambos habían muerto sin nombrar tutores y curadores testamentarios de sus hijos menores.

Lo que no acostumbraban hacer los notarios cristianos, cuando aludían a una carta pública de asignación de tutores y curadores por los jueces judíos, era insertar en su protocolo, como documento unido, la carta pública de tutela y curadela, escrita en hebreo. Claro que Pedro Sánchez de Calatayud, el notario que insertó en su protocolo de 1436 una carta pública de tutela y curadela, escrita así, había sido judío, se llamó Jehuda Galluf y debió de conocer la lengua hebrea ${ }^{1}$.

Antes de saber quiénes fueron las personas nombradas en esta carta pública de tutela y curadela, conviene recordar que el nombramiento de tutores y curadores dativos ${ }^{2}$ no recaía, necesariamente,

\footnotetext{
${ }^{1}$ Una fotocopia del original la entregué a mi compañero José Luis Lacave para su edición. Vid. este mismo fascículo de Sefarad págs. 283-284.

${ }^{2}$ La influencia «del fuero y observancia del reino» en las comunidades judías aragonesas aparece clara en los nombramientos de tutores y curadores dativos, aunque en el caso de los testamentarios se especificara, además, que se aplicaría la «ley e pratiqua de judios».
} 
sobre los familiares del menor, aunque solía aceptarse la propuesta familiar que optaba por el cónyuge sobreviviente, el abuelo o abuela, el hermano o hermana mayor, o un pariente cercano del pupilo.

El tutor y curador dativo, asignado por los jueces judíos en esta carta de tutela y curadela, fue Jehuda Avenlopiel ${ }^{3}$, corredor de número de Zaragoza, del que se desconoce su relación con los pupilos judíos, Bienvenist, Jamila y Lopa Arruet, hijos de Juce Arruet, judío de La Almunia de Doña Godina, muerto abintestato.

La orfandad de los menores, por parte de madre, debió de ser la razón de que el notario no aludiera a esta al referirse al difunto Juce Arruet, que estaría emparentado con los judíos de La Almunia, Mosse Arruet, casado con Jamila Constantin, padres de otro Juce Arruet, cuya hija Ester, menor de edad, estuvo a servicio de Juce Frances dos años.

El interesante dato de la relación familiar del tutor y curador zaragozano con los menores, que no especificó el notario, quizás hubiera explicado que fueran los «berurines, si quiere judges de la aliama de los jodios de la dita ciudat de Çaragoca», quienes se ocuparan de la designación, en vez de hacerlo los adelantados de la aljama judía de La Almunia de Doña Godina, quienes años después actuarían como jueces de esa comunidad ${ }^{4}$.

\footnotetext{
${ }^{3}$ Escrito también Abenlopiel y Abenlupiel. En 1405 en Zaragoza, el «cirurgico» judío de la ciudad, Bitas Abenforna, actuó como procurador de otro judío de su misma residencia, Jehuda Abenlupiel, que pasó a vivir a Épila, villa del señorío de los Ximénez de Urrea (Zaragoza, Archivo de Protocolos Notariales [= Z.APN.], Lázaro Marcén, 1405, fol. 74v). Es posible que volviera a Zaragoza, porque el 21 de abril de 1420 , en dicha ciudad, el converso zaragozano Martín Pérez de Moros -antes Avon Avenlopiel- vendió a su convecino judío Jehuda Abenlopiel «hun sitio siquiere lugar de posar que yo he, sitiado en la sinoga Mayor de los jodios de la dita ciudat, et todo et qualquiere dreyto et accion que yo he en aquel, que afruenta con sitio de Facen Giniello, con sitio de Simuel Albarginoni et con rescondiello», por treinta sueldos (véase A. BLASCO MARTíneZ, La judería de Zaragoza en el siglo XIV [Zaragoza 1988] pág. 140, nota 798). Años después, el 14 de abril de 1433, Jehuda Abenlopiel era uno de los siete diputados que «toda la aljama» de los judíos de Zaragoza «e concello de aquella» nombraron para efectuar la venta de un «troz de la casa que solia seyer sinoga, clamada la sinoga de la Alhaquim» (véase E. MARín PADILlA, «Nota sobre una sinagoga de Zaragoza, la de "Alhaquim", Sefarad 56 [1996] págs. 437-438). Transcurridos tres años tuvo lugar su nombramiento como tutor y curador dativo de los tres hijos menores de Juce Arruet.

${ }^{4}$ Por ejemplo, cuando nombraron: el 2 de diciembre de 1444, tutores de las personas y bienes de los menores Solliqua, Estruguiqua y Alazarico Ferrer, hijos de Alazar Ferrer, a la madre de los niños Azibuena y a Simuel Atortox; el 2 de
} 
Dicho esto, paso a referirme al citado instrumento público notarial.

El 26 de julio de 1436, en Zaragoza, el corredor de número Jehuda Avenlopiel, sin «injeccion alguna» y como tutor y curador de las personas y bienes de Bienvenist, Jamila e Lopa Arruet, pupilos hijos de Juce Arruet, judío del lugar de La Almunia de Doña Godina, muerto abintestato, vendió al también judío de La Almunia, Açach Taboch, los cien sueldos que sus convecinos Juan Cabrera y su mujer Antona Polo tenían en comanda del difunto Juce Arruet ${ }^{5}$, junto con todo y cualquier derecho y acción que les perteneciera cobrar a dichos pupilos. Los cien sueldos del precio otorgó haberlos recibido ${ }^{6} ; \mathrm{y}$ "prengo quinyan con quinyan complido en poder de Jento Chiniello» 7.

El nombramiento de Jehuda Avenlopiel, como tutor y curador de las personas y bienes de los tres menores Arruet, fue

dado et assignado por Açach Abenarguaz e Jento Gallur, jodios berurines, si quiere judges de la aliama de los jodios de la dita ciudat de Çaragoca, segunt que de la dita tutella e cura consta por carta feyta en la dita ciudat ... a dezesiet dias del mes de junio clamado Tamuz del anyo que se contava a Nativitate domini MCCCCXXX quarto e al conto de los jodios del anyo del creamiento del mundo de cinquo mil cient novanta e quatro, testifficada por Vidal Avulfada, notario de la dita aliama.

\footnotetext{
agosto de 1486, tutores y curadores de las personas y bienes de los pupilos Alazarico y Reynica Alpullat, hijos de Jehuda Alpullat, a su abuela materna Aljohar Cohen, viuda de Jaco Carillo, y a Simuel de Leon, judío de Daroca; y el siguiente día 20, tutor y curador de la menor Cinha Cohen, hija de Abraham Cohen, a su tío carnal Hahim Cohen, alias Montañés. A todo lo relativo al nombramiento de tutores y curadores dativos en el seno de la comunidad judía de La Almunia de Doña Godina me referí ampliamente en E. MARín PAdilla, «Los judíos de La Almunia de Doña Godina, villa aragonesa de señorío, en la segunda mitad del siglo XV», Sefarad 49 (1989) págs. 135-152 y 263-306, 50 (1990) págs. 85-127 y 335-371, y 51 (1991) págs. 51-84 y 299-337: 49 (1989) págs. 266-269 y 50 (1990) págs. 345-347 y 368-369.

${ }^{5}$ Según carta pública de esta, hecha el 24 de marzo de 1420 , ante el notario real y vecino de La Almunia de Doña Godina Pedro Ximénez de Soteras.

${ }^{6}$ Siguen fórmulas jurídicas de garantía.

7 Z.APN., Pedro Sánchez de Calatayud, 1436, fols. 8v-9: fueron testigos los vecinos de Zaragoza, el mercader Nicolás de Pueyo y los judíos, Simuel Almalcani y el sastre Jento Chiniello.
} 
Pues bien, la carta pública de esta asignación, escrita en hebreo, es la que insertó el notario converso Pedro Sánchez de Calatayud en su protocolo, como justificante de la actuación de Jehuda Avenlopiel al vender la comanda.

Quiero añadir para terminar que en mis estudios sobre la comunidad judía de La Almunia de Doña Godina ${ }^{8}$, de fecha posterior a la de la asignación de tutor y curador de los tres hijos menores del difunto Juce Arruet, no aparece el nombre de ninguno de estos pupilos ${ }^{9}$. ¿Se los llevó a Zaragoza su tutor y curador Jehuda Abenlopiel? Posiblemente los judíos de la familia Arruet de La Almunia de Doña Godina, a los que me referí en dichos estudios, fueron parientes de los menores y quizás alguno un hermano mayor no citado en la carta de asignación de tutor y curador por no considerarlo necesario.

\section{RESUMEN}

La autora da noticia de un instrumento público de venta del Archivo de Protocolos Notariales de Zaragoza, que testificó el notario de la ciudad Pedro Sánchez de Calatayud en 1436. En él se inserta, como documento unido, una carta pública de tutela y curadela escrita en hebreo.

\section{SUMMARY}

The author presents a short description of a document she discovered in the Zaragoza Notarial Archives to which the Calatayud notary Pedro Sánchez bore witness in 1436. Attached to it, as evidence, is a public writ of guardianship written in Hebrew.

${ }^{8}$ El citado en nota 4 y E. MARín PADILlA, «Pleito por el señorío de la judería de La Almunia de Doña Godina en 1486», en Homenaje a J. M. ${ }^{a}$ Lacarra (Príncipe de Viana XLVII 1986) págs. 507-523.

${ }^{9}$ ¿Fue el judío Bienvenist Arruet, documentado en Arándiga, el único hijo varón del difunto Juce Arruet? A él me referí en E. MARín PADILLA, «La villa de Arándiga, del señorío de los Martínez de Luna, en el siglo XV: sus judíos», Sefarad 57 (1997) págs. 69-95 y 277-306, 58 (1998) págs. 271-298, 59 (1999) págs. 101-125 y 319-342, y 60 (2000) págs. 127-142: 58 (1998) pág. 290. 